\title{
Prostate Cancer Awareness Among Women: A Mixed-methods Systematic Review
}

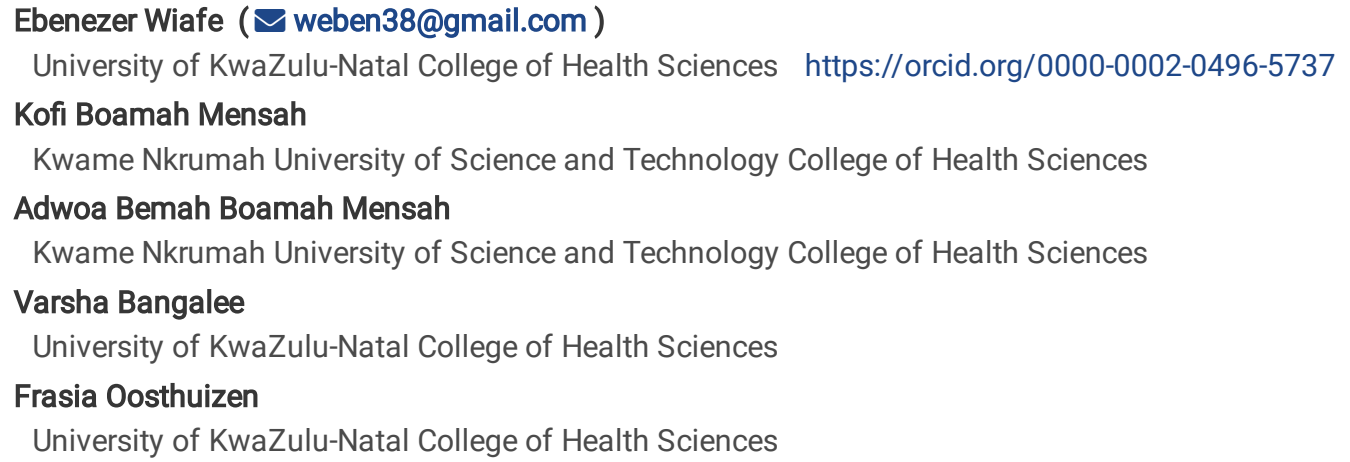

\section{Research}

Keywords: Awareness, Signs and symptoms, Causes and risk factors, Screening recommendations, Prostate cancer, Women

Posted Date: December 8th, 2020

DOI: https://doi.org/10.21203/rs.3.rs-121896/v1

License: (c) (i) This work is licensed under a Creative Commons Attribution 4.0 International License. Read Full License 


\section{Abstract}

Background: With the burden of prostate cancer, it has become imperative to exploit cost-effective ways to tackle this menace. Women have demonstrated their ability to recognize early cancer signs and it is therefore relevant to include women in strategies to improve the early detection of prostate cancer. This systematic review seeks to gather evidence from studies that investigated women's knowledge about; (1) the signs and symptoms, (2) causes and risk factors, and (3) the screening modalities of prostate cancer. Findings from the review will better position women in the fight against the late detection of prostate cancer.

Methods: The convergent segregated approach to the conduct of mixed-methods systematic reviews was employed. Five databases namely; MEDLINE (EBSCOhost), CINAHL (EBSCOhost), PsycINFO (EBSCOhost), Web of Science, and EMBASE (Ovid) were searched from January 1999 to December 2019 for studies conducted with a focus on the knowledge of women on the signs and symptoms; the causes and risk factors; and the screening modalities of prostate cancer.

Results: Of 2201 titles and abstracts screened, 22 full-text papers were retrieved and reviewed, and 7 were included: 3 quantitative, 1 qualitative, and 3 mixed-methods studies. Both quantitative and qualitative findings indicate that women have moderate knowledge of the signs and symptoms; and the causes and risk factors of prostate cancer. However, women recorded poor knowledge about prostate cancer screening modalities or tools.

Conclusions: Moderate knowledge of women on the signs and symptoms, and the causes and risk factors of prostate cancer were associated with education. These findings provide vital information for the prevention and control of prostate cancer and encourage policy-makers to incorporate health promotion and awareness campaigns in health policies to improve knowledge and awareness of prostate cancer globally.

Systematic Review registration number: Open Science Framework (OSF) registration DOI: https://doi.org/10.17605/OSF.IO/BR456

\section{Background}

Prostate cancer ( $\mathrm{PCa}$ ) is the most common non-skin cancer occurring in men and is accountable for $3.8 \%$ of all mortality caused by cancer in men $(1,2)$. According to the GLOBOCAN, 2018 database, it is estimated that it is the fifth primary cause of cancer death in men globally. It further reported that the highest mortality rate is found in the Caribbean and Southern African men worldwide $(1,3)$. A recent study by YeboahAsiamah et al. reported that PCa was the second most common cancer in areas such as Australia, the United States, and New Zealand (4). Though fewer than $30 \%$ of all incidence of PCa are from developing countries, these countries have previously been estimated to have the highest mortality from PCa due to late diagnosis $(5,6)$. Although sub-Saharan Africa (SSA) has a low rate of the disease, the incidence is projected to increase if screening is encouraged (7). Hence, PCa remains a vital public health concern in both developed and developing countries.

The Centers for Disease Control and Prevention (CDC) in North America, organized a workshop with the motive to explore strategies to control and prevent the disease based on the increasing incidence and mortality rate of $\mathrm{PCa}$ (8). To address mortality rates related to the disease, participants recommended strategies to improve PCa awareness (8). Also, as documented by many studies, PCa incidence is a direct reflection of the rate at which high-risk groups screen for the disease $(4,9)$. In Europe, early screening was attributed to a $20 \%$ reduction in PCa mortality rate (10). Although there is evidence suggesting a reduction in PCa mortality due to early screening, a United States (US) study did not highlight a reduction in mortality (11). The prostate-specific antigen (PSA) test and the digital rectal examination (DRE) are useful screening tools, although initial controversies were surrounding the use of these tools (12). Because of overlap in PSA levels in men with prostatitis, benign prostatic hyperplasia, and PCa, it was assumed that PCa cannot be screened using the PSA test (13). Catalona et al. demonstrated that PSA could be utilized as a screening tool for PCa and it has widely been adopted (14). DRE is the only procedure whereby physicians can examine part of the prostate gland (15). The findings are only based on the physician impression, hence poor inter-rater reliability and also a limitation to the palpable region of the prostate gland (15). However, DRE sometimes detects PCa in men with PSA, $4.0 \mathrm{ng} / \mathrm{mL}$ (16). Regardless of the controversial nature of screening and the potential for early screening to reduce mortality, studies support the need to encourage screening (4, 12).

Women have essential characteristics that make them better managers of family health as compared to men. Therefore, it is not surprising that there is evidence positioning women as individuals who make adequate observations about the health of their partners $(9,17)$. In promoting the early detection of $\mathrm{PCa}$, women have been documented to observe the slightest symptoms presented by their partners and push them to seek medical attention $(9,18)$. In a study conducted by Blanchard et al., it was recommended that efforts must be made to actively involve women in improving the timely detection of PCa through the closure of knowledge-gaps (19).

Also, men admit seeking out their wives' opinions as sources of health information (20). In the context of the early detection of PCa, women can play various roles such as information seekers, advocates, health advisors, and support persons (21). Therefore, there is the need to gather 
current evidence about women's knowledge of PCa as the findings will be vital in equipping women to contribute towards the early detection of the disease.

In light of the availability of limited evidence addressing the awareness of women on prostate cancer, this review will seek to combine quantitative and qualitative data to increase the validity of findings through data triangulation as recommended by Caruth and supported by Lizarondo et al. $(22,23)$. Thus, this review seeks to map out current evidence regarding women's awareness of PCa under the scopes of; 1 ) signs and symptoms, 2) risk factors and causes, and 3) screening guidelines.

\section{Methodology}

The Joanna Briggs Institute (JBI) reviewer's manual for the conduct of mixed-methods critical appraisal and synthesis formed the backbone of the study (23). With guidance from the JBI manual, a protocol was developed to guide the review process according to the convergent segregated approach (23). The respective DOls of the review protocol and review, registered with the Open Science Framework (OSF), are https://doi.org/10.17605/OSF.IO/EYHF2 and https://doi.org/10.17605/OSF.IO/BR456.

\section{Inclusion criteria}

We considered studies that were published in English and peer-reviewed journals between January 1999 and December 2019. Included studies were selected from primary research of any methodology; and explored awareness on signs and symptoms, causes and risk factors, and screening of prostate cancer. Studies that were conducted among women regardless of the geographical location were included. Studies that were mainly conducted in men were excluded in addition to studies not published in the English language.

\section{Information sources and search strategy}

An initial explorative search in PubMed founded search terms in preparation for comprehensive electronic search. The selected search terms were combined with Boolean operators for a comprehensive electronic search in MEDLINE (EBSCOhost), CINAHL (EBSCOhost), PsycINFO (EBSCOhost), Web of Science, and EMBASE (Ovid) as "(prostate cancer) AND (awareness OR knowledge) AND (signs OR symptoms) AND (risk factors OR causes) AND (screening) AND (women)". The search strategy (Appendix 1), so developed, was utilized by the first (EW) and second (KBM) reviewers to independently conduct a literature search as outlined in the review protocol (24).

\section{Selection of studies}

The first and second reviewers, being guided by the developed review protocol, singularly screened and compared the titles and abstracts of the literature search outcomes to a developed standard (Appendix 2). Studies that successfully passed the initial stage of screening were subjected to the independent full-text reading by EW and KBM before consideration for data extraction. Lastly, hand-searching and snowballing on references of selected articles were done to find eligible studies in the grey area. There were no disagreements between EW and KBM. Hence, the third reviewer (ABBM) assessed the studies before data extraction was conducted by the lead author according to the JBI data extraction tools outlined in the review protocol (24). The characteristic of studies that successfully went through the data extraction, the key findings that were extracted, and a summary of the study selection process are detailed respectively (Table 1, Table 2, and Fig. 1). 
Table 1

Characteristics of selected studies

\begin{tabular}{|c|c|c|c|c|c|c|c|}
\hline $\begin{array}{l}\text { AUTHOR } \\
\text { AND } \\
\text { YEAR }\end{array}$ & COUNTRY(S) & $\begin{array}{l}\text { ETHNIC/CULTURAL } \\
\text { BACKGROUND(S) }\end{array}$ & $\begin{array}{l}\text { STUDY } \\
\text { POPULATION }\end{array}$ & $\begin{array}{l}\text { OTHER } \\
\text { CONDITIONS/DOMAINS } \\
\text { STUDIED }\end{array}$ & $\begin{array}{l}\text { RESEARCH } \\
\text { DESIGN }\end{array}$ & $\begin{array}{l}\text { LENGTH } \\
\text { OF } \\
\text { STUDY }\end{array}$ & $\begin{array}{l}\text { SAMPLE } \\
\text { SIZE OF } \\
\text { INTEREST } \\
\text { POPULATION }\end{array}$ \\
\hline $\begin{array}{l}\text { Blanchard } \\
\text { et al., } \\
2005\end{array}$ & $\begin{array}{l}\text { United } \\
\text { States }\end{array}$ & $\begin{array}{l}\text { Caucasians/Whites, } \\
\text { African- } \\
\text { Americans/Blacks, } \\
\text { Hispanics/Whites, } \\
\text { and } \\
\text { Hispanics/Blacks }\end{array}$ & Women & None. & $\begin{array}{l}\text { Quantitative } \\
\text { study }\end{array}$ & Missing & 324 \\
\hline $\begin{array}{l}\text { Brown et } \\
\text { al., } 2006\end{array}$ & $\begin{array}{l}\text { United } \\
\text { States }\end{array}$ & $\begin{array}{l}\text { African-Americans } \\
\text { and Afro- } \\
\text { Caribbeans }\end{array}$ & Women & $\begin{array}{l}\text { Heart health, breast } \\
\text { health, prostate health, } \\
\text { second-hand smoke, } \\
\text { asthma, and sexual } \\
\text { health. }\end{array}$ & $\begin{array}{l}\text { Cross- } \\
\text { sectional } \\
\text { quantitative } \\
\text { study }\end{array}$ & $\begin{array}{l}\text { Five (5) } \\
\text { days }\end{array}$ & 221 \\
\hline $\begin{array}{l}\text { Carrasco- } \\
\text { Garrido et } \\
\text { al., } 2014\end{array}$ & Spain & Spanish & $\begin{array}{l}\text { Men and } \\
\text { women }\end{array}$ & $\begin{array}{l}\text { Colorectal cancer, } \\
\text { breast cancer, and } \\
\text { cervical cancer. }\end{array}$ & $\begin{array}{l}\text { Population- } \\
\text { based } \\
\text { cross- } \\
\text { sectional } \\
\text { mixed- } \\
\text { methods } \\
\text { study }\end{array}$ & $\begin{array}{l}\text { Two (2) } \\
\text { months }\end{array}$ & $\begin{array}{l}4040(50.9 \% \\
\text { of } 7938)\end{array}$ \\
\hline $\begin{array}{l}\text { Okoro et } \\
\text { al., } 2018\end{array}$ & $\begin{array}{l}\text { United } \\
\text { States }\end{array}$ & $\begin{array}{l}\text { Black/African- } \\
\text { Americans }\end{array}$ & $\begin{array}{l}\text { Men and } \\
\text { women }\end{array}$ & None. & $\begin{array}{l}\text { Cross- } \\
\text { sectional } \\
\text { mixed } \\
\text { methods } \\
\text { study }\end{array}$ & $\begin{array}{l}\text { Three } \\
\text { (3) } \\
\text { months }\end{array}$ & 297 \\
\hline $\begin{array}{l}\text { Owens et } \\
\text { al., } 2015\end{array}$ & $\begin{array}{l}\text { United } \\
\text { States }\end{array}$ & African-Americans & $\begin{array}{l}\text { Men and } \\
\text { women }\end{array}$ & None. & $\begin{array}{l}\text { Mixed } \\
\text { methods } \\
\text { study }\end{array}$ & $\begin{array}{l}\text { About } 2 \\
\text { months }\end{array}$ & 38 \\
\hline $\begin{array}{l}\text { Schulman } \\
\text { et al., } \\
2003\end{array}$ & $\begin{array}{l}\text { France, } \\
\text { Germany, } \\
\text { Italy, Spain, } \\
\text { Sweden, } \\
\text { United } \\
\text { Kingdom, } \\
\text { and the } \\
\text { United } \\
\text { States }\end{array}$ & $\begin{array}{l}\text { Western Europeans } \\
\text { and Americans }\end{array}$ & $\begin{array}{l}\text { Men and } \\
\text { women }\end{array}$ & $\begin{array}{l}\text { Breast cancer, lung } \\
\text { cancer, bowel cancer, } \\
\text { heart disease, stroke, } \\
\text { diabetes }\end{array}$ & $\begin{array}{l}\text { Quantitative } \\
\text { study } \\
\text { (Telephone } \\
\text { interview) }\end{array}$ & $\begin{array}{l}\text { Nineteen } \\
(19) \\
\text { days }\end{array}$ & 700 \\
\hline $\begin{array}{l}\text { Webb et } \\
\text { al., } 2006\end{array}$ & $\begin{array}{l}\text { United } \\
\text { States }\end{array}$ & $\begin{array}{l}\text { Blacks (non- } \\
\text { Hispanics) and } \\
\text { Hispanics/Latinos }\end{array}$ & $\begin{array}{l}\text { Men and } \\
\text { women }\end{array}$ & None. & $\begin{array}{l}\text { Qualitative } \\
\text { study } \\
\text { (Focus } \\
\text { group } \\
\text { discussion) }\end{array}$ & Missing & 14 \\
\hline
\end{tabular}


Table 2

Summarized study findings

$\begin{array}{lll}\text { STUDY FINDINGS } & \text { CONCLUSION LIMITATIONS }\end{array}$

Knowledge, Attitudes and Beliefs of Women about the Importance of Prostate Cancer

Screening (Blanchard et al., 2005)
1. The mean score for women's knowledge about prostate cancer and screening guidelines was determined to be $6.99 \pm 3.54$ out of 15 points. 2 . Educational level and income were discovered to have increased the mean score for women's knowledge. 3. Women who disclosed their familiarity with cancer of the prostate and available screening recommendations recorded higher scores in knowledge assessment. 4. Only 54.3\% of women knew about the asymptomatic presentation of prostate cancer in early stages. 5 . About $37 \%$ of women failed to recognize age as a risk factor for prostate cancer. $6.83 .9 \%$ of women were of the known that men, symptomatic or not, should screen for prostate cancer. $7.54 \%$ of married and $42 \%$ of single women recognized the early detection of prostate cancer as the key importance of screening. 8. Married (41\%) and single (32\%) women agreed that men feared prostate cancer screening results as well as the application of the digital rectal examination for screening.
Women are not knowledgeable about prostate cancer. An educational intervention model, targeting women, could equip women to contribute to the early detection

of prostate cancer by encouraging men to screen routinely for the disease.

1. Women might not have documented true responses to questionnaire items since a self-reporting technique was employed in the study. 2. The study was limited to only women fluent in the English language and hence, findings could not be extended to cover all women in New Orleans. 3. The use of the convenience sampling method in the study exposed the study to participants selection bias and hence, a negative impact on the generalization of study findings.

Assessment of preventive health knowledge and

behaviors of AfricanAmerican and AfroCaribbean women in urban

settings

(Brown et al., 2006).
1. Generally, the knowledge score of women on the symptoms of prostate cancer was appreciable. 2. Women who knew about the existence of prostate cancer in their families had higher knowledge scores. 3. 24\% of women responded prostate cancer is asymptomatic; whilst $65 \%, 67 \%$, and $63 \%$ respectively noted the difficulty in passing urine, dysuria, and the need to frequently pass urine as symptoms. 4 . Women found it difficult in identifying tools applicable to prostate cancer screening. 5. $46 \%, 61 \%$, and $38 \%$ of women respectively selected prostate-specific antigen (PSA), digital rectal examination (DRE), and x-ray as prostate cancer screening tools.
Women are

more

knowledgeable

about the

prostate cancer

but know very

little about

prostate cancer

screening tools.

An intervention

is needed to

upgrade the

knowledge of

women on the symptoms and screening tools applicable to symptoms of prostate cancer.

1. The study suffered various forms of selection bias as the participants were conveniently selected from salons that were interested in the health promotion initiatives of the Arthur Ashe Institute for Urban Health (AAIUH). 2. The study was restricted to women who used the services of the selected salons and hence, the study findings could not be a true reflection of all New York women. 3.

There was an observation of a high number of correctly answered questions.

Awareness and uptake

1. $51.56 \%$ of Spanish women knew PSA as a prostate cancer screening tool. of colorectal,

2. Education and social status significan
PSA as a prostate cancer screening tool.

breast, cervical, and

prostate

cancer

screening

tests in

Spain

(Carrasco-

Garrido et

al., 2014).
The use of antigen (PSA) for prostate cancer screening is poorly known to women. Women should be comprehensively educated on screening tools. prostate-specific
1. The validity and reliability of the survey instrument were not done in the study population. 2.

Respondents might have given socially acceptable responses when their awareness about PSA was tested. 3. Women who knew about PSA as a prostate cancer screening tool might have been high in the study. 


\begin{tabular}{|c|c|}
\hline $\begin{array}{l}\text { STUDY } \\
\text { TITLE }\end{array}$ & FINDINGS \\
\hline $\begin{array}{l}\text { Leveraging } \\
\text { the Family } \\
\text { Influence of } \\
\text { Women in } \\
\text { Prostate } \\
\text { Cancer } \\
\text { Efforts } \\
\text { Targeting } \\
\text { African } \\
\text { American } \\
\text { Men (Okoro, } \\
\text { Rutherford, \& } \\
\text { Witherspoon, } \\
\text { 2018). }\end{array}$ & $\begin{array}{l}\text { 1. On a } 25 \text { knowledge-score scale, women's mean score was } 11.4 \pm 5.1 \text {. } 2 \text {. No } \\
\text { idea accounted for } 29.1 \% \text { of women's responses to prostate cancer } \\
\text { knowledge. } 3 \text {. The focused group discussion involving women revealed an } \\
\text { overall poor prostate cancer knowledge. } 4 \text {. The PSA as a prostate cancer } \\
\text { confirmatory tool and the recommended age for universal prostate cancer } \\
\text { screening received the worst correct response rates. } 5 \text {. Only } 17.5 \% \text { of women } \\
\text { knew elevated PSA levels did not exclusively indicate the existence of } \\
\text { prostate cancer. } 6 \text {. As low as } 13.5 \% \text { of women knew universal prostate } \\
\text { cancer screening is not exclusively a recommendation for only men above } \\
50 \text { years. } 7 \text {. The educational status of women greatly increased knowledge } \\
\text { scores. } 8.62 .3 \%, 57.2 \% \text {, and } 38.7 \% \text { of women respectively identified the } \\
\text { presence of a first-degree relative, being a man of African descent and } \\
\text { excessive truncal obesity as risk factors of prostate cancer. } 9 \text {. Women } \\
\text { (54.5\%) knew the asymptomatic nature of prostate cancer. } 10.47 .5 \% \text { of } \\
\text { women recognized DRE as a tool for the early detection of prostate cancer. } \\
11 . \text { Women (40.7\%) indicated the need for risk assessment before the } \\
\text { initiation of prostate cancer screening; whilst } 54.2 \% \text { agreed with the } \\
\text { recommendation that men who are } 40-45 \text { years and are at risk for the } \\
\text { development of the disease should seek adequate health information from } \\
\text { registered healthcare providers. }\end{array}$ \\
\hline
\end{tabular}

CONCLUSION LIMITATIONS

The knowledge and awareness of women about prostate cancer are not appreciable. An educational intervention model can increase prostate cancer awareness and knowledge among women.
1. The study included only African-American women and hence, findings cannot be extended to cover all women in America. 2. The study suffered selection bias as participants were conveniently sampled.

3. The survey instrument did not undergo validation and reliability assessment in the study population. 4 . The study engaged relatively young participants and hence findings could not be an exact representation of all age groups. 5 . The study participants, being young, might have accounted for the observed low knowledge scores.

1. The relatively small sample size of interest population hindered results generalizability. 2. The study was limited to African-Americans and hence, findings could not be generalized to cover other races/ethnic diversities in the study site. 3. The participants were conveniently sampled and hence, the poor generalizability of results.

Friedman, \&

Hébert,

2015).

\section{Awareness} of prostate cancer among the general public: Findings of an independent international survey (Schulman, Kirby, \& Fitzpatrick, 2003).
1. 100 women each from 7 countries were involved in the study. $2.28 \%$ of female respondents spontaneously included prostate cancer in their list of available cancers whilst $69 \%$, who didn't initially list prostate cancer, agreed to the existence of the disease when asked a closed-ended question. 3 . Women in the United Kingdom (40\%), United States (20\%), France (23\%), Germany (24\%), Italy (21\%), Spain (26\%), and Sweden (39\%) were spontaneously aware of prostate cancer. When prompted, additional respective $58 \%, 76 \%, 70 \%, 75 \%, 76 \%, 69 \%$ and $61 \%$ of women recognized the existence of prostate cancer. 4. Women in Spain (36\%), the United States (35\%), Italy (23\%), Sweden (22\%), the United Kingdom (17\%), France (17\%), and Germany (9\%) recognized PSA as a prostate cancer screening tool. 5. $20 \%$ of women in the United States, $14 \%$ in France, $8 \%$ in Spain, $6 \%$ in the United Kingdom, 6\% in Germany, 5\% in Italy, and 2\% in Sweden recognized DRE as a prostate cancer screening tool. 6 . Mistakenly, $37 \%$ of women in Spain, $22 \%$ in Italy, $17 \%$ in France, $13 \%$ in the United Kingdom, $10 \%$ in Germany, $11 \%$ in Sweden, and 5\% in the United States recognized the use of urine as a prostate cancer screening sample. 7 . The inability of women to recognize at least a prostate cancer screening tool followed the trend: Germany (71\%), Sweden (60\%), the United Kingdom (56\%), the United States (53\%), France (52\%), Italy (44\%) and Spain (41\%).
The recognition of the basic prostate cancer screening tools by women was very low. The general awareness of prostate cancer was lacking in women. To promote the early detection of prostate cancer in an attempt to reduce mortality, and educational intervention targeting women is needed.
1. The study failed to indicate the percentage of women who were able to identify the signs and symptoms, and risk factors of prostate cancer. 2. The number of participants from the various countries was relatively small to promote the generalizability of results. 3. Respondents might have given socially approved responses since data collection was through a telephone interview. 4. The validity and reliability of the questionnaire were not determined in the study population. 


\begin{tabular}{|c|c|c|c|}
\hline $\begin{array}{l}\text { STUDY } \\
\text { TITLE }\end{array}$ & FINDINGS & CONCLUSION & LIMITATIONS \\
\hline $\begin{array}{l}\text { An } \\
\text { evaluation } \\
\text { of the } \\
\text { knowledge, } \\
\text { attitudes, } \\
\text { and beliefs } \\
\text { of African- } \\
\text { American } \\
\text { men and } \\
\text { their female } \\
\text { significant } \\
\text { others } \\
\text { regarding } \\
\text { prostate } \\
\text { cancer } \\
\text { screening } \\
\text { (Webb, } \\
\text { Kronheim, } \\
\text { Williams, \& } \\
\text { Hartman, } \\
\text { 2006). }\end{array}$ & $\begin{array}{l}\text { 1. Women disclosed that prostate cancer may occur in men who are or } \\
\text { greater than } 65 \text { years old. However, women were not sure if a diet has } \\
\text { caused a reduction in the age at which men develop prostate cancer. } 2 \text {. } \\
\text { During the FDG, some women agreed that prostate cancer screening starts } \\
\text { when men celebrate their } 40 \text { tht birthday. } 3 \text {. The use of blood as a screening } \\
\text { sample for prostate cancer detection was mentioned by women. However, } \\
\text { women reported the need for a physical body examination in addition to } \\
\text { blood analysis. }\end{array}$ & $\begin{array}{l}\text { The knowledge } \\
\text { women posses } \\
\text { about prostate } \\
\text { cancer screening } \\
\text { have } \\
\text { appreciable } \\
\text { gaps. Educating } \\
\text { women on } \\
\text { prostate cancer } \\
\text { screening is of } \\
\text { equal } \\
\text { importance as } \\
\text { male prostate } \\
\text { cancer } \\
\text { education. }\end{array}$ & $\begin{array}{l}\text { 1. Results have low } \\
\text { generalizability due to } \\
\text { the utilization of the } \\
\text { convenience sampling } \\
\text { strategy. } 2 \text {. Validity } \\
\text { and reliability studies } \\
\text { of the FGD questions } \\
\text { were not done in the } \\
\text { study population. } 3 \text {. } \\
\text { The target number of } \\
\text { study subjects needed } \\
\text { for the FDG was not } \\
\text { met. Hence, the study } \\
\text { sample was } \\
\text { inadequate. }\end{array}$ \\
\hline
\end{tabular}

\section{Quality assessment}

As described in the review protocol (24), the methodological quality assessment tool (Appendix 3) was adopted and modified for this review (25). The tool appraised the studies' quality based on the studies sample representativeness, response rate, reliability, and validity of the data collection tool. The tool was modified to suit the results from the included studies. A score was calculated, and the quality of the studies was classified as weak (0-33.9\%), moderate (34-66.9\%), or strong (67-100\%). Eligible records were subjected to independent quality assessment by EW and KBM. Methodological quality outcomes were not grounds for exclusion.

\section{Synthesis and integration of findings}

The review findings were subjected to the convergent segregated approach to synthesis and integration according to the developed review protocol (24). A narrative synthesis was separately performed for qualitative and quantitative findings. The results were finally integrated.

\section{Results}

Conducting the review, according to the developed protocol, yielded 2200 studies results. A detailed citation screening led to an additional study, which increased the total studies to 2201. Regarding the summary of the study selection process (Fig. 1), 1672 studies were obtained after 529 duplicates were removed from the pool of data. Post- titles and abstracts review excluded 1650 studies leaving 22 studies. The 22 studies were further reduced to 7 after a full-text reading resulted in the exclusion of 15 studies.

\section{Characteristics of included studies}

The data extracted from the seven (7) studies are detailed (Table 1). The publication years ranged from 2003 to 2018 with 5 studies having been conducted in the United States. One of the studies was a multicenter study that involved multinationals (26). The study with the highest female participants (4040 women) was conducted in Spain (27). Webb et al. recruited the lowest sample size, 14 women (28). A total of 5634 women were involved in the 7 studies. Two studies were solely conducted in women, three included other diseases, and two did not disclose study duration.

\section{Quality of included studies}

According to the scoring scheme of the quality assessment tool (Appendix 3$)$, two studies $(27,28)$ were evaluated as moderate-quality whilst five studies were evaluated as strong quality. None of the studies were excluded based on methodological quality assessment outcomes. There was no disagreement between EW and KBM.

\section{Review findings}

Study findings, presented in Table 2, were heterogeneous. Quantitative studies indicate that women knew about the existence of PCa. In exploring qualitative evidence, women exhibited knowledge of PCa. Therefore, both arms of the review are supportive of each other.

Women had moderate knowledge about the signs and symptoms of PCa drawing from quantitative findings. The asymptomatic nature of early staged PCa; and women moderately knew urinary symptoms such as urinary frequency, difficulty in urinating, and dysuria. Qualitative studies 
indicate that women were aware of signs and symptoms such as urinary frequency, difficulty in urinating, glandular enlargement of the prostate, and erectile dysfunction. Hence, quantitative and qualitative findings revealed that women moderately knew the urinary symptoms of PCa.

Quantitative studies indicate an average score of women on knowledge of risk factors of PCa. Risk factors women knew were increasing age, presence of a first-degree relative, being genetically linked to Africa, and excessive truncal obesity. Qualitative evidence recognized all risk factors documented by the quantitative findings except truncal obesity. Also, identified risk factors included poor diet, inadequate exercise, stressful lifestyle, poor screening habits, cigarette smoking, and poor access to quality healthcare. Women wrongly reported sexual orientation and frequent sexual activity as risk factors. Therefore, qualitative findings confirm the quantitative claim that women have shared knowledge about the risk factors of PCa.

Quantitative studies indicate that women had poor knowledge about PCa screening. Although it was reported that women knew about PSA and DRE, knowledge scores were significantly low. Also, women poorly recognized urine as a screening sample, PSA as an exclusive diagnostic tool, and failed to identify more than one screening tool. Qualitative studies respectively reported PSA and blood as a screening tool and sample. Colonoscopy was wrongly reported as a PCa screening tool. Conclusively, both arms of the review reported women knew about PSA and had poor knowledge about PCa screening.

\section{Discussion}

The heterogeneity of the study findings warranted the synthesis as a narrative $(23,29)$. The convergent segregated approach was employed according to the recommendation of the JBI reviewer's manual (23).

Generally, from the quantitative evidence, women knew about prostate cancer $(19,26,30,31)$. The knowledge of women was found to have increased with educational and financial status (19); and disease familiarity $(19,31)$. The awareness of women about the existence of PCa increased when the disease was mentioned compared to an initial request for women to list cancers (26). Qualitative evidence showed that women were aware of PCa $(18,30)$. They appreciated and specifically requested for PCa education partly because they could not tell the location of the prostate gland (18). Thus, quantitative and qualitative evidence indicates that women know about PCa. Women's awareness could be due to their role in family health management and the possible health-seeking behavior of educated and financially strong women. As persons are faced with the experiences of a health condition, they will seek to make sense of this illness by acquiring knowledge (32), experiences, and beliefs; hence this theory might explain the improved awareness of women who were familiar with the disease.

Most of the quantitative studies indicate that women are aware of the asymptomatic nature of early-stage PCa (19, 30, 31). Symptoms that women had a fair knowledge about included urinary frequency, difficulty in urinating, and dysuria (31). Findings from one of the qualitative studies indicate that women fairly recognized urinary frequency, difficulty in urinating, glandular enlargement of the prostate, and erectile dysfunction as signs and symptoms of PCa (18). Being familiar with the disease may explain the awareness of women of the urinary symptoms associated with PCa.

According to Okoro and colleagues' quantitative study, although knowledge of PCa was not adequate, women knew associated risk factors such as being a first-degree relative, being a man of African descent, and excessive truncal obesity (30). Blanchard et al. also documented women's recognition of increasing age as a PCa risk factor (19). One of the qualitative studies indicates women knew increasing age could increase a man's chance for PCa development $(18,28)$. Other causes and risk factors women identified included poor diet, inadequate exercise, stressful lifestyle, family history of the disease, being of African descent, poor screening habits, cigarette smoking, and poor access to quality healthcare (18). Erroneously, one study reported that women perceived sexual orientation and frequent sexual activity as risk factors (18). Both quantitative and qualitative findings documented women knew increasing age, family history, and African descent as PCa risk factors.

Quantitatively, women's responses to queries about PCa screening was poor $(26,31)$. Some women were unable to recognize at least a PCa screening tool whilst others mistakenly recognized urine as a suitable sample for PCa screening (26). According to Okoro et al. the majority of women exclusively tagged PSA elevation as a basis for PCa diagnosis (30). This, therefore, calls for extensive education because benign prostatic hyperplasia, prostatitis, and PCa usually present with elevated PSA (13). Evidence from qualitative findings indicated women knew physical examination must augment blood analysis (28). Also, women mentioned PSA and colonoscopy as screening tools (18). The results from included qualitative studies confirmed that women had poor knowledge about PCa screening. The mention of colonoscopy as a screening tool further supports a lack of adequate knowledge about PCa screening.

This critical appraisal and synthesis revealed over the 20 years of study search, only four studies out of the seven included studies investigated all the outcomes of interest. Two studies did not investigate women's awareness of the signs and symptoms (27, 28) and the causes and risk factors $(27,31)$ of PCa. Therefore, although quantitative and qualitative findings were supportive of each other, studies investigating the causes and risk factors, as well as the signs and symptoms of PCa, were lacking.

Page $8 / 12$ 


\section{Recommendations For Practice}

From the review findings, it is recommended that PCa control programs should also focus on educating women. Clinicians and public health practitioners should include women in prostate cancer health promotion. Women should be encouraged to attend PCa clinics with their male significant others suffering from the disease and the effect of this strategy in reducing PCa mortality rate investigated.

\section{Recommendations For Research}

Further studies are recommended to investigate the knowledge of women living in low and middle-income countries (LMIC) about PCa. Such studies should focus extensively on the knowledge of women on PCa screening. Also, it is recommended for research to develop and pilot a PCa educational intervention model, applicable to women to reduce the burden of the disease. This tool should be cultural-specific for easy acceptance and recognition. Also, current evidence on the willingness of women to offer social support to men with PCa should be investigated.

\section{Study Limitations}

The various restrictions that were imposed on the literature search included a search range from January 1999 to December 2019 , a search into only 5 databases, and the outright exclusion of non-English publications.

Other limitations were the exclusion of studies conducted in women who received education on prostate cancer, healthcare professionals, healthcare students, and college/university students, and further exclusion of studies that involved (LGBTQ) participants.

\section{Abbreviations}

$\mathrm{CDC}$

Centers for Disease Control and Prevention; DRE:digital rectal examination; GLOBOCAN:Global Cancer Incidence, Mortality and Prevalence; JBI:Joanna Briggs Institute; LGBTQ:Lesbian, Gay, Bisexual, Transsexual/transgender, and Queer/questioning; OSF:Open Science Framework; LMIC:Iow and middle-income countries; PCa:Prostate cancer; PSA:prostate-specific antigen; SSA:sub-Saharan Africa; US:United States.

\section{Declarations}

\section{Ethics approval and consent to participate}

Ethical permission was not required since the study did not involve the enrollment of humans or animals as study subjects.

\section{Consent for publication}

None.

\section{Availability of Data and Materials}

Data and other pieces information are available at; https://doi.org/10.17605/OSF.IO/BR456

\section{Competing Interests}

None.

\section{Funding}

None.

\section{Authors' Contributions}

EW is credited with the conception of the review, the coordination of the systematic review, the development of the search strategy, the search and selection of studies to be included in the review, the extraction and management of quantitative and qualitative data, the assessment of methodological quality, the filtering of all reference materials, the integration and interpretation of the data, the drafting of the manuscript and is the principal reviewer. KBM is credited with the conception of the review, the review of the search strategy, the search and selection of studies to be included in the review, the extraction and management of quantitative and qualitative data, the assessment of methodological quality, the integration and interpretation of the data and the review of the manuscript. ABBM is credited with the review of the search strategy, the assessment of the studies before data extraction, and the review of the manuscript. VB is credited with the review of the manuscript, the 
coordination of the systematic review, and the co-supervisor of the review. FO is credited with the conception of the review, the review of the manuscript, and the overall supervision of the review. All authors have reviewed and accepted the final manuscript of the review for publication.

\section{Acknowledgment}

The review team gives recognition to Dr. Richard Ofori-Asenso.

\section{References}

1. Bray F, Ferlay J, Soerjomataram I, Siegel RL, Torre LA, Jemal A. Global cancer statistics 2018: GLOBOCAN estimates of incidence and mortality worldwide for 36 cancers in 185 countries. CA: a cancer journal for clinicians. 2018;68(6):394-424.

2. James LJ, Wong G, Craig JC, Hanson CS, Ju A, Howard K, et al. Men's perspectives of prostate cancer screening: A systematic review of qualitative studies. PloS one. 2017.

3. GLOBOCAN. GLOBOCAN 2008: Ghana Fact Sheets. 2018 [Available from: file:///C:/Users/user-pc/Downloads/288-ghana-fact-sheets.pdf.

4. Yeboah-Asiamah B, Yirenya-Tawiah D, Baafi D, Ackumey M. Perceptions and knowledge about prostate cancer and attitudes towards prostate cancer screening among male teachers in the Sunyani Municipality, Ghana. African Journal of Urology. 2017;23(4).

5. Rebbeck TR, Devesa SS, Chang B-L, Bunker CH, Cheng I, Cooney K, et al. Global patterns of prostate cancer incidence, aggressiveness, and mortality in men of african descent. Prostate cancer. 2013;2013.

6. Mofolo N, Betshu O, Kenna O, Koroma S, Lebeko T, Claassen FM, et al. Knowledge of prostate cancer among males attending a urology clinic, a South African study. SpringerPlus. 2015;4(1):67.

7. Jemal A, Bray F, Forman D, O'Brien M, Ferlay J, Center M, et al. Cancer burden in Africa and opportunities for prevention. Cancer. 2012;118(18):4372-84.

8. Dimah KP, Dimah A. Prostate cancer among African American men: A review of empirical literature. Journal of African American Studies. 2003;7(1):27-46.

9. Rashid P, Denham J, Madjar I. Do women have a role in early detection of prostate cancer? Lessons from a qualitative study. Australian family physician. 2007;36(5):375.

10. Schröder FH, Hugosson J, Roobol MJ, Tammela TL, Ciatto S, Nelen V, et al. Screening and prostate-cancer mortality in a randomized European study. New England Journal of Medicine. 2009;360(13):1320-8.

11. Andriole GL, Crawford ED, Grubb III RL, Buys SS, Chia D, Church TR, et al. Mortality results from a randomized prostate-cancer screening trial. New England Journal of Medicine. 2009;360(13):1310-9.

12. Nakandi H, Kirabo M, Semugabo C, Kittengo A, Kitayimbwa P, Kalungi S, et al. Knowledge, attitudes and practices of Ugandan men regarding prostate cancer. African Journal of Urology. 2013;19(4):165-70.

13. Catalona WJ. Prostate cancer screening. Medical Clinics. 2018;102(2):199-214.

14. Catalona WJ, Smith DS, Ratliff TL, Dodds KM, Coplen DE, Yuan JJ, et al. Measurement of prostate-specific antigen in serum as a screening test for prostate cancer. New England Journal of Medicine. 1991;324(17):1156-61.

15. Wilbur J. Prostate cancer screening: the continuing controversy. American family physician. 2008;78(12):1377-84.

16. Federman DG, Pitkin P, Carbone V, Concato J, Kravetz JD. Screening for prostate cancer: are digital rectal examinations being performed? Hospital practice. 2014;42(2):103-7.

17. Karim R, Lindberg L, Wamala S, Emmelin M. Men's perceptions of Women's participation in development initiatives in rural Bangladesh. American journal of men's health. 2018;12(2):398-410.

18. Owens OL, Friedman DB, Hebert J. Commentary: Building an Evidence Base for Promoting Informed Prostate Cancer Screening Decisions: An Overview of a Cancer Prevention and Control Program. Ethnicity \& disease. 2017;27(1):55.

19. Blanchard K, Proverbs-Singh T, Katner A, Lifsey D, Pollard S, Rayford W. Knowledge, attitudes and beliefs of women about the importance of prostate cancer screening. Journal of the National Medical Association. 2005;97(10):1378-85.

20. Taylor KL, Turner RO, Davis III JL, Johnson L, Schwartz MD, Kerner J, et al. Improving knowledge of the prostate cancer screening dilemma among African American men: an academic-community partnership in Washington, DC. Public Health Reports. 2016.

21. Miller SM, Roussi P, Scarpato J, Wen KY, Zhu F, Roy G. Randomized trial of print messaging: the role of the partner and monitoring style in promoting provider discussions about prostate cancer screening among African American men. Psycho-Oncology. 2014;23(4):404-11.

22. Caruth GD. Demystifying Mixed Methods Research Design: A Review of the Literature. Mevlana International Journal of Education. 2013;3(2):112-22.

23. Lizarondo L, Stern C, Carrier J, Godfrey C, Rieger K, Salmond S, et al. Chapter 8: Mixed methods systematic reviews.: The Joanna Briggs Institute; 2017 [Available from: https://wiki.joannabriggs.org/display/MANUAL/Chapter+8\%3A+Mixed+methods+systematic+reviews.

Page 10/12 
24. Wiafe E, Mensah KB, Mensah ABB, Bangalee V, Oosthuizen F. The awareness of women on prostate cancer: a mixed-methods systematic review protocol. Systematic Reviews. 2020;9(1):1-6.

25. Mensah KB, Oosthuizen F, Bonsu AB. Cancer awareness among community pharmacist: a systematic review. BMC cancer. 2018;18(1):299.

26. Schulman CC, Kirby R, Fitzpatrick JM. Awareness of prostate cancer among the general public: Findings of an independent international survey. European Urology. 2003;44(3):294-302.

27. Carrasco-Garrido P, Hernandez-Barrera V, Lopez de Andres A, Jimenez-Trujillo I, Gallardo Pino C, Jimenez-Garcia R. Awareness and uptake of colorectal, breast, cervical and prostate cancer screening tests in Spain. European journal of public health. 2014;24(2):264-70.

28. Webb CR, Kronheim L, Williams JE, Hartman TJ. An evaluation of the knowledge, attitudes, and beliefs of African-American men and their female significant others regarding prostate cancer screening. Ethnicity \& Disease. 2006;16(1):234-8.

29. Lockwood C, Porritt K, Munn Z, Rittenmeyer L, Salmond S, Bjerrum M, et al. Chapter 2: Systematic reviews of qualitative evidence: The Joanna Briggs Institute; 2017 [Available from: https://wiki.joannabriggs.org/display/MANUAL/Chapter+2\%3A+Systematic+reviews+of+qualitative+evidence.

30. Okoro ON, Rutherford CA, Witherspoon SF. Leveraging the Family Influence of Women in Prostate Cancer Efforts Targeting African American Men. Journal of Racial and Ethnic Health Disparities. 2018;5(4):820-30.

31. Brown N, Naman P, Homel P, Fraser-White M, Clare R, Browne R. Assessment of preventive health knowledge and behaviors of AfricanAmerican and Afro-Caribbean women in urban settings. Journal of the National Medical Association. 2006;98(10):1644-51.

32. Petrie K, Weinman J. Why illness perceptions matter. Clinical Medicine. 2006;6(6):536.

\section{Figures}

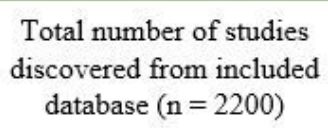

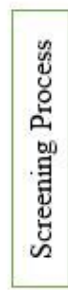
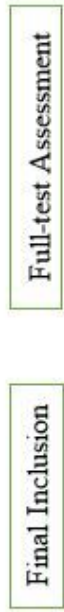

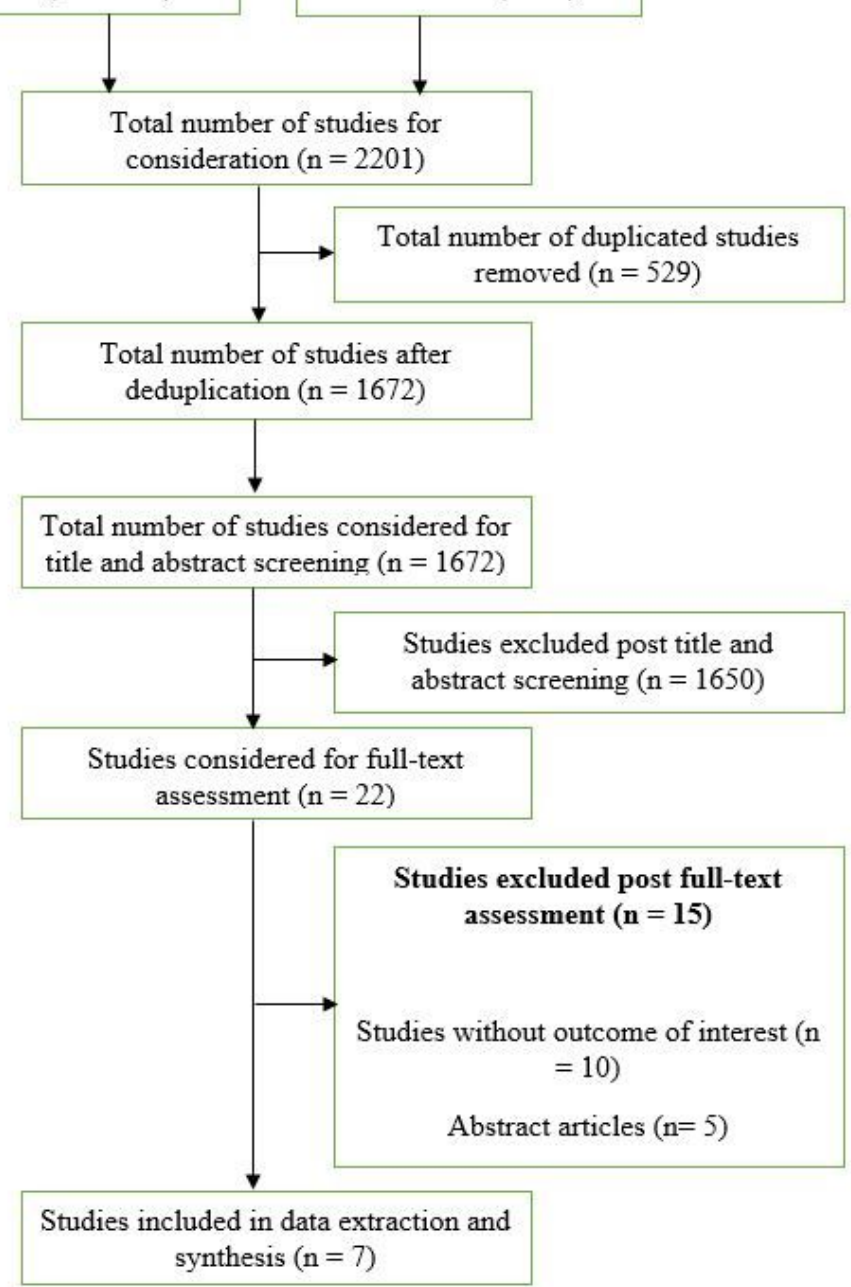

Page $11 / 12$ 


\section{Figure 1}

Summary of study selection process.

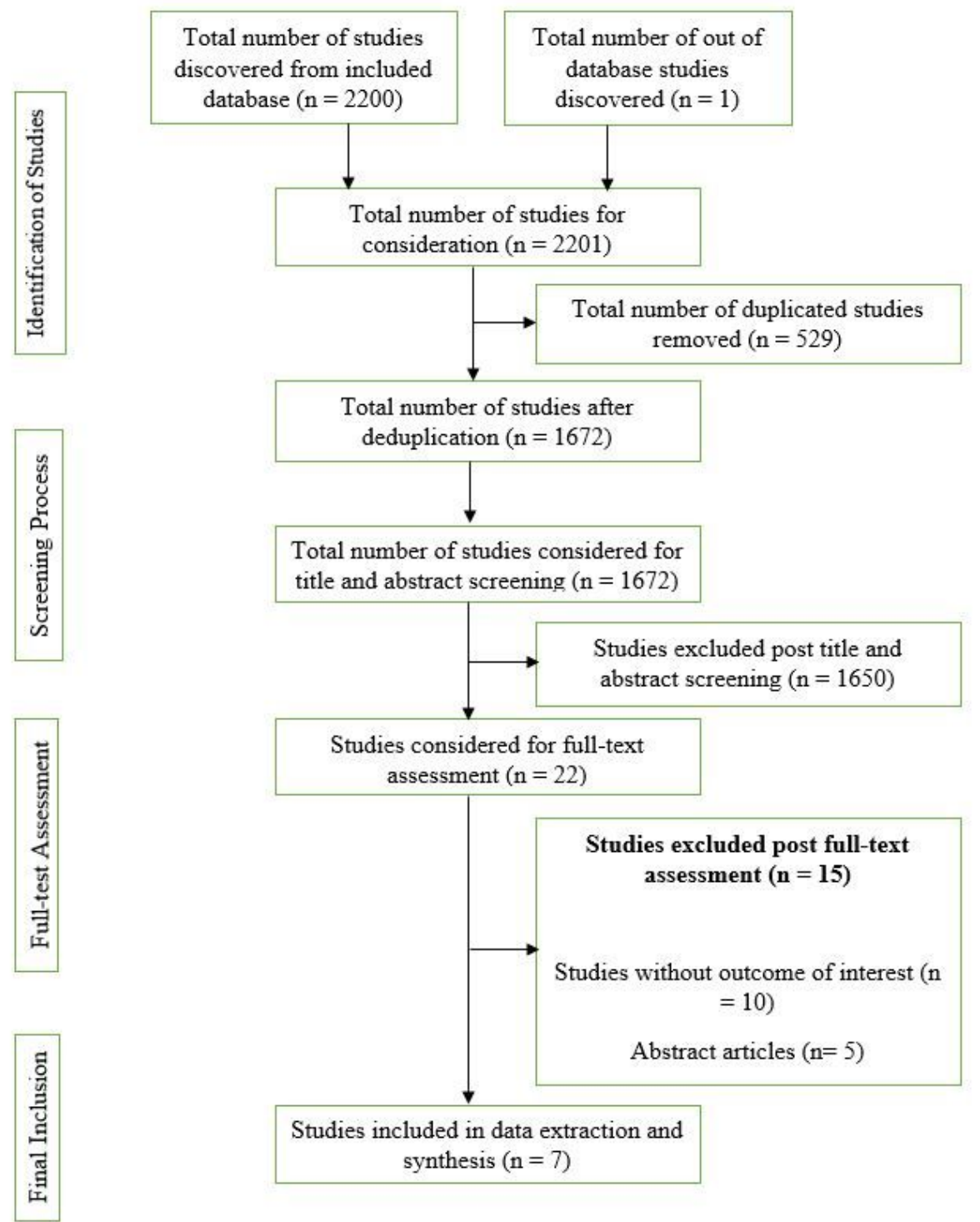

Figure 1

Summary of study selection process.

\section{Supplementary Files}

This is a list of supplementary files associated with this preprint. Click to download.

- APPENDIX1SEARCHSTRATEGY.docx

- APPENDIX1SEARCHSTRATEGY.docX

- APPENDIX2INCLUSIONANDEXCLUSIONCRITERIA.docX

- APPENDIX2INCLUSIONANDEXCLUSIONCRITERIA.docX

- APPENDIX3QUALITYASSESSMENT.docX

- APPENDIX3QUALITYASSESSMENT.docX

- PRISMAPchecklist.docx

- PRISMAPchecklist.docx 